\title{
REVIEW ARTICLE \\ Risk of transmitting meningococcal infection by transient contact on aircraft and other transport
}

\author{
T. RACHAEL ${ }^{1 *}, K$ KCHUBERT ${ }^{2}$, W. HELLENBRAND ${ }^{2}$, G. KRAUSE ${ }^{2}$ \\ AND J. M. STUART ${ }^{1,3}$ \\ ${ }^{1}$ Health Protection Agency, London, UK \\ ${ }^{2}$ Robert Koch Institute, Berlin, Germany \\ ${ }^{3}$ University of Bristol, Bristol, UK
}

(Accepted 11 February 2009; first published online 19 March 2009)

\section{SUMMARY}

Contact tracing of persons with meningococcal disease who have travelled on aeroplanes or other multi-passenger transport is not consistent between countries. We searched the literature for clusters of meningococcal disease linked by transient contact on the same plane, train, bus or boat. We found reports of two clusters in children on the same school bus and one in passengers on the same plane. Cases within each of these three clusters were due to strains that were genetically indistinguishable. In the aeroplane cluster the only link between the two cases was through a single travel episode. The onset of illness ( 2 and 5 days after the flight) is consistent with infection from an unidentified carrier around the time of air travel. In contrast to the established risk of transmission from a case of tuberculosis, it is likely that the risk from a case of meningococcal disease to someone who is not identified as a close contact is exceedingly low. This should be considered in making international recommendations for passenger contact tracing after a case of meningococcal disease on a plane or other multi-passenger transport.

Key words: Aircraft, epidemiology, meningococcal disease, transient contact, transmission.

\section{INTRODUCTION}

Guidelines for the public health management of transient contacts of persons with meningococcal disease on aeroplanes and other means of travel vary widely across Europe [1]. Chemoprophylaxis is recommended for plane passengers who are seated adjacent to, in the same row, the row in front or behind such a person for periods between 4 and $10 \mathrm{~h}$ depending on the country, and some countries do not recommend that fellow travellers should routinely receive chemoprophylactic treatment at all [2]. USA

\footnotetext{
* Author for correspondence: Miss T. Rachael, Primary Care Department, Kingshill House, Kingshill Road, Swindon, Wiltshire, SN1 4LG, UK.

(Email: tia_rachael@hotmail.com)
}

guidelines from the Centers for Disease Control and Prevention (CDC) recommend that chemoprophylaxis be considered for passengers seated directly next to an index case on an aircraft for at least $8 \mathrm{~h}$ [3].

The CDC guidelines are based on a World Health Organisation (WHO) report on tuberculosis and air travel [4]. This states that passengers should be offered chemoprophylaxis if seated in the same row or two rows ahead and behind a diagnosed case of tuberculosis for at least $8 \mathrm{~h}$. This report was based on seven investigations into transmission of tuberculosis on aeroplanes, one of which documented transmission to six fellow passengers with no risk factors seated in the same section of a long flight [5].

As policies for contact tracing vary so widely between countries and do not appear to be evidence 
Table 1. Clusters of meningococcal disease associated with the same transport

\begin{tabular}{|c|c|c|c|c|c|c|c|}
\hline Study & $\begin{array}{l}\text { No. of } \\
\text { cases } \\
\text { linked }\end{array}$ & $\begin{array}{l}\text { Interval } \\
\text { between } \\
\text { cases }\end{array}$ & $\begin{array}{l}\text { Mode of } \\
\text { transport }\end{array}$ & $\begin{array}{l}\text { Duration } \\
\text { of contact }\end{array}$ & $\begin{array}{l}\text { Method of } \\
\text { diagnosis }\end{array}$ & Serogroup & Subtype \\
\hline Harrison et al. [6] & 5 & 2 & School bus & - & $\begin{array}{l}\text { Culture (blood/ } \\
\text { CSF) }\end{array}$ & $\mathrm{C}(n=5)$ & $\begin{array}{l}\text { Indistinguishable } \\
\text { electrophoretic isoenzyme } \\
\text { type }\end{array}$ \\
\hline O'Connor et al. [8] & 2 & 3 & Aircraft & $14 \cdot 5 \mathrm{~h}$ & PCR (CSF) & $\mathrm{B}(n=2)$ & Indistinguishable genotype \\
\hline Beard et al. [7] & 2 & 2 & School bus & - & PCR (CSF) & $\mathrm{B}(n=2)$ & Indistinguishable genotype \\
\hline
\end{tabular}

based, we conducted a literature search of meningococcal disease in passengers travelling with an index case.

\section{METHODS}

Databases searched were Medline (1950 to 1 August 2007) and EMBASE (1974 to 1 August 2007). Each database was searched separately and duplicates removed. Articles were identified which included both a meningococcal disease key term and a travel key term anywhere in the article content. The search strategy was not restricted by language. A list of possible MESH search terms for each database was identified and searched in addition to 'textwords'.

Search terms used were 'Neisseria meningitidis', 'meningitis-meningococcal', 'meningococcal infection(s)', 'meningococcosis', 'meningococcal disease', 'travel', 'transport', 'transportation', 'passenger', 'journey', 'aircraft', 'aviation', 'aviation accidents', 'flight', 'flying', 'aircraft-accident', 'aircraft', 'air travel', 'ship(s)', 'cruise', 'ocean liner', 'boat', 'ferry', 'railroads', 'railway', 'locomotive', 'motor vehicle(s)', 'traffic-and-transport', 'automobile', 'bus', 'coach', 'traffic', 'transportation-of-patients', 'patient-transport'. For the complete search strategy, see Appendix.

Titles and available abstracts were used to decide which articles potentially met inclusion criteria. Fulltext articles were obtained when more information was needed or if inclusion criteria were met. Articles met inclusion criteria if they contained information on cases of meningococcal disease that occurred in conjunction with a flight or while using any other multi-passenger transport. Articles citing cases of meningococcal disease associated with more than transient contact, i.e. travel companions or school excursions, were excluded. Reference lists of full-text articles obtained were searched for relevant articles.
Other case reports known to the authors were also examined.

\section{RESULTS}

The search identified 541 references, of which 28 fulltext articles were obtained. Three papers included evidence to suggest transmission of meningococci on aeroplanes or buses, while four further articles described single cases of meningococcal infection on flights.

Three articles in the literature describe clusters of meningococcal disease linked only by contact while travelling (Table 1). Harrison et al. [6] document five cases of serogroup $\mathrm{C}$ meningococcal disease in children who travelled regularly on the same school bus. No other links were found between the cases and the authors concluded that transmission had occurred on the school bus. Beard et al. [7] also describe two serogroup B cases where the only evidence of contact was on a crowded school bus each day. A third article by O'Connor et al. [8] reports two cases of serogroup B meningococcal disease with onset 2 and 5 days after travelling on the same international flight from Los Angeles to Sydney. These two cases were seated 12 rows apart; one reported regular walks around the aircraft, while the other was seated in an aisle seat. Chemoprophylaxis was provided to those seated adjacent to, in front of, and behind each case, in accordance with Australian and USA guidelines.

The meningococcal strains from cases within each of these three clusters were indistinguishable by genotyping. Harrison et al. [6] reported the use of electrophoretic isoenzyme testing which found all five cases had a rare and identical isoenzyme pattern. Beard et al. [7] reported that por $A /$ por $B$ genotyping yielded identical sequences; none of the serogroup $B$ isolates that year in the same geographical area had an 
equivalent serotype/serosubtype. O'Connor et al. [8] reported similar results, where standard methodologies of siaD/por $A /$ por $B$ sequencing and multi-locus sequence typing found the same allelic profile for both cases. Again, no isolates had the same subtype/ serosubtype that year in Australia.

Our literature search also generated four papers that documented meningococcal disease in passengers of long duration flights without known occurrence of secondary cases. CDC [9] received 21 reports of airtravel-associated meningococcal disease (defined as a patient with invasive meningococcal disease within 14 days of travel on a flight of at least $8 \mathrm{~h}$ duration) between February 1999 and May 2001, of whom five were symptomatic during the flight and 16 developed symptoms 1-10 days after the flight. No secondary cases or links between these cases were described. However, this was a passive surveillance system and chemoprophylaxis may have been offered to those seated adjacent to the identified cases as recommended by CDC [3]. In a report by Riley [10], symptomatic meningococcal disease in a passenger on an 11-h charter flight led to active contact tracing of over 200 fellow passengers, an unspecified number of whom received chemoprophylaxis. A case of serogroup W135 meningococcal disease with symptomatic onset on a flight from Japan to Singapore was described by Wilder-Smith \& Goh [11] with no mention of contact tracing. Another single case of symptomatic meningococcal disease in a student on an 11-12 h flight was reported by Bar-Oz \& Loughran [12]. Close contacts including those on the student tour group were recommended to receive chemoprophylaxis. No secondary cases were reported after any of these cases.

Two additional reports not listed in Medline or EMBASE of cases of meningococcal disease in air travellers were known to the authors. A report from Canada [13] describes well the difficulties of comprehensive contact tracing after a case on a flight from India. No secondary cases were observed, but all contacts seated up to two rows in front and behind and four seats laterally were successfully contacted and received rifampicin. A patient with symptomatic meningococcal disease on a 3-h flight from Madrid to Berlin is described in the German national epidemiological bulletin [14]. Because the passenger was reported to have been coughing and because there had been free seating on the plane, all passengers were notified and advised to contact their physician regarding possible chemoprophylaxis. No secondary cases were reported (W. Hellenbrand, personal communication).

\section{DISCUSSION}

Only three reports of clusters of meningococcal disease linked through contact on transport were identified. In two of these reports the link was through regular travel on the same school bus. The cases in each of these two clusters could therefore be considered as part of the same social network. The only cluster in which the cases were linked through a single travel episode was on a long-distance plane flight. In addition, we found reports of 26 similar exposures that did not result in known secondary cases, although in some of these cases, antibiotic prophylaxis was provided to close contacts. Publication bias would undoubtedly favour reports on exposures that resulted in secondary cases rather than in exposures that did not.

It is important to distinguish between the risk of transmission from cases of tuberculosis and of meningococcal disease. The CDC guidelines for contact tracing in transient contacts of cases of meningococcal disease are based on evidence of tuberculosis transmission on aeroplanes in a small number of follow-up studies [4]. The ' $8 \mathrm{~h}$ ' recommendation is based on these studies of tuberculosis transmission. No such evidence is available for transmission of meningococci. Transmission of tuberculosis via aerosol occurs through the deposit of infective droplet nuclei ( $<5 \mu \mathrm{m}$ in diameter) in the lung from persons with active pulmonary disease [15]. In contrast, Neisseria meningitidis is transmitted primarily through larger respiratory droplets as its natural habitat is the nasopharynx [16]. It is not known whether the dry environment in aircrafts might facilitate the formation of droplet nuclei or what effect it would have on large droplet transmission. In both cases transmission is primarily limited to persons having prolonged close contact. The pattern of air circulation in aeroplanes from ceiling to floor with little air flow from front to back, as well as the filtration of recirculated air with HEPA-type filters would make proximity an even stronger prerequisite for droplet transmission in aircraft $[17,18]$.

Following transmission of tuberculosis, most individuals remain asymptomatic. A small minority develop active disease after a latent period of weeks to years [4]. Transmission of meningococci in most cases leads only to colonization. A wide range of estimates 
for the duration of carriage has been published, ranging from a median of 4-20 months and a mean of 6-29 months [19-22]. The risk of disease given colonization with serogroups $\mathrm{B}$ or $\mathrm{C}$ has been estimated to range from $\sim 0.0004$ to as high as 0.1 in infants [23], with a higher risk after colonization with serogroup C than serogroup B. However, as the spectrum of meningococcal genotypes causing disease differs from that found in colonization studies [24], this risk is likely to be higher from carriers of a more virulent clonal complex. Although close (household) contacts of cases of invasive meningococcal disease have a higher risk of disease [25], surveillance data have shown that $<3 \%$ of all cases are secondary cases, implying that most transmission occurs from asymptomatic carriers [26, 27]. This is consistent with the observation that cases are only colonized for a very short period before onset of disease [28] such that they pose a similarly brief risk to others. In all of the clusters reported here, the onset of disease in the cases could be explained by a point-source exposure to an asymptomatic carrier. All of these factors make the assessment of risk of disease in aircraft passengers exposed to a case of meningococcal disease exceedingly difficult. In conclusion, we found no convincing evidence of the transmission of meningococcal infection from a case arising from transient contact on aeroplanes or other multi-passenger transport. However, due to the dispersal of passengers and the risk from asymptomatic carriers, it is also feasible that travel-related transmission might not be recognized. Guidance for contact tracing on board aircraft and other transport needs urgent review with the objective of achieving consistency of approach through risk assessment. The ECDC has embarked on this exercise $[29,30]$. The evidence presented in this review should contribute to the development of internationally agreed recommendations.

\section{APPENDIX}

\section{Full search strategy and results}

\begin{tabular}{|c|c|c|c|}
\hline No. & Database & Search term & Results \\
\hline 1 & Medline 1950-2007 & $\begin{array}{l}\text { Neisseria-meningitidis.de. OR meningitis-meningococcal.de. OR } \\
\text { meningococcal-infections.de. }\end{array}$ & 8310 \\
\hline 2 & Medline 1950-2007 & $\begin{array}{l}\text { travel.w..de. OR transportation.w..de. OR aircraft.w..de. OR aviation.w..de. OR } \\
\text { accidents-aviation.de. OR ships.w..de. OR motor-vehicles.de. OR railroads.w..de. } \\
\text { OR transportation-of-patients.de. }\end{array}$ & 37017 \\
\hline 3 & & 1 AND 2 & 85 \\
\hline 4 & Medline 1950-2007 & $\begin{array}{l}\text { meningococcal disease OR Neisseria-meningitidis OR meningococcal infection } \\
\text { OR meningococcosis }\end{array}$ & 10140 \\
\hline 5 & Medline 1950-2007 & $\begin{array}{l}\text { passenger OR journey OR travel OR aircraft OR aviation OR flight OR flying } \\
\text { OR aircraft accident OR aviation accident OR transport OR patient transport } \\
\text { OR transportation OR motor vehicle OR automobile OR bus OR coach OR train } \\
\text { OR cruise OR ocean liner OR ship OR boat OR ferry OR locomotive OR railway } \\
\text { OR railroad OR traffic }\end{array}$ & 478899 \\
\hline 6 & & 4 AND 5 & 296 \\
\hline 7 & EMBASE 1974-2007 & Neisseria-meningitidis.de. OR meningococcosis.w..de. & 8572 \\
\hline 8 & EMBASE 1974-2007 & $\begin{array}{l}\text { travel.w..de. OR patient-transport.de. OR aviation.w..de. OR flight.w..de. } \\
\text { OR flying.w..de. OR aircraft-accident.de. OR ship.w..de. OR motor-vehicle.de. } \\
\text { OR traffic-and-transport.de. OR railway.w..de. }\end{array}$ & 23180 \\
\hline 9 & & 7 AND 8 & 130 \\
\hline 10 & EMBASE 1974-2007 & $\begin{array}{l}\text { meningococcal disease OR Neisseria-meningitidis OR meningococcal infection } \\
\text { OR meningococcosis }\end{array}$ & 9292 \\
\hline 11 & EMBASE 1974-2007 & $\begin{array}{l}\text { passenger OR journey OR travel OR aircraft OR aviation OR flight OR flying } \\
\text { OR aircraft accident OR aviation accident OR transport OR patient transport } \\
\text { OR transportation OR motor vehicle OR automobile OR bus OR coach OR train } \\
\text { OR cruise OR ocean liner OR ship OR boat OR ferry OR locomotive OR railway } \\
\text { OR railroad OR traffic }\end{array}$ & 432814 \\
\hline 12 & & 10 AND 11 & 387 \\
\hline 13 & & Combined sets $3,6,9,12$ & 898 \\
\hline 14 & & Dropped duplicates from 13 & 358 \\
\hline 15 & & Unique records from 13 & 541 \\
\hline
\end{tabular}




\section{DECLARATION OF INTEREST}

None.

\section{REFERENCES}

1. Hoek M, et al. A European survey on public health policies for managing cases of meningococcal disease and their contacts. Eurosurveillance 2008; 13: 8060.

2. Health Protection Agency Meningococcus Forum. Guidance for public health management of meningococcal disease in the UK, 2006. London: Health Protection Agency.

3. Centers for Disease Control and Prevention. Guidelines for the management of airline passengers exposed to meningococcal disease. 2005 (http://wwwn.cdc.gov/ travel/contentMenin.aspx.2007). Accessed 6 April 2008.

4. WHO. Tuberculosis and air travel: guidelines for prevention and control. Geneva: World Health Organization, 2006.

5. Kenyon TA, et al. Transmission of multidrug-resistant mycobacterium tuberculosis during a long airplane flight. New England Journal of Medicine 1996; 334: 933-938.

6. Harrison LH, et al. A cluster of meningococcal disease on a school bus following epidemic influenza. Archives of Internal Medicine 1991; 151: 1005-1009.

7. Beard FH, et al. Probable transmission of meningococcal disease on a school bus. Medical Journal of Australia 2006; 184: 190.

8. O'Connor BA, et al. Meningococcal disease - probable transmission during an international flight. Communicable Disease Intelligence 2005; 29 : 312-314.

9. Centers for Disease Control and Prevention. Exposure to patients with meningococcal disease on aircrafts United States, 1999-2001. Morbidity and Mortality Weekly Reports 2001; 50: 485-489.

10. Riley LK. Bacterial meningitis exposure during an international flight: lessons for communicable pathogens. Aviation, Space, and Environmental Medicine 2006; 77 : 758-760.

11. Wilder-Smith A, Goh KT. W-135 Meningococcal disease in a traveler: a case report. Journal of Travel Medicine 2003; 10: 59-60.

12. Bar-Oz B, Loughran B. Antibiotics and airline emergency kits. Emerging Infectious Diseases 2003; 9: $757-758$

13. Department of Social Services and Community Health GoA. Meningitis on an aircraft, Alberta, Canada. Epidemiologic Notes and Reports of Communicable Disease Control and Epidemiology 1987; 11: 60-62.

14. Robert Koch-Institut. Measures after invasive meningococcal disease in an aircraft passenger. Epidemiologisches Bulletin 2005; 24: 207.

15. Beggs CB, et al. The transmission of tuberculosis in confined spaces: an analytical review of alternative epidemiological models. International Journal of Tuberculosis and Lung Disease 2003; 7: 1015-1026.

16. Taha MK, et al. The duality of virulence and transmissibility in Neisseria meningitidis. Trends in Microbiology 2002; 10: 376-382.

17. Leder K, Newman D. Respiratory infections during air travel. Internal Medicine Journal 2005; 35: 50-55.

18. Mangili A, Gendreau MA. Transmission of infectious diseases during commercial air travel. Lancet 2005; 365 : 989-996.

19. De Wals P, Bouckaert A. Methods for estimating the duration of bacterial carriage. International Journal of Epidemiology 1985; 14: 628-634.

20. Trotter CL, Gay NJ. Analysis of longitudinal bacterial carriage studies accounting for sensitivity of swabbing: an application to Neisseria meningitidis. Epidemiology and Infection 2003; 130: 201-205.

21. Riordan T, et al. Acquisition and carriage of meningococci in marine commando recruits. Epidemiology and Infection $2000 ; 121$ : 495-505.

22. Pether JV, et al. Carriage of Neisseria meningitidis: investigations in a military establishment. Epidemiology and Infection 1988; 101: 21-42.

23. Trotter CL, Gay NJ, Edmunds WJ. The natural history of meningococcal carriage and disease. Epidemiology and Infection 2006; 134: 556-566.

24. Yazdankhah SP, et al. Distribution of serogroups and genotypes among disease-associated and carried isolates of Neisseria meningitidis from the Czech Republic, Greece, and Norway. Journal of Clinical Microbiology 2004; 42: 5146-5153.

25. Purcell B, et al. Effectiveness of antibiotics in preventing meningococcal disease after a case: systematic review. British Medical Journal 2004; 328: 1339-1343.

26. Hastings $\mathbf{L}$, et al. A retrospective survey of clusters of meningococcal disease in England and Wales, 1993 to 1995: estimated risks of further cases in household and educational settings. Communicable Disease Report 1997; 7: R195-R200.

27. Centers for Disease Control and Prevention. Prevention and control of meningococcal disease. Morbidity and Mortality Weekly Reports 2005; 54: 1-21.

28. Edwards EA. Immunological investigations of meningococcal disease. II. Some characteristics of group C antigen of Neisseria meningitidis in the sera of patients with fulminant meningococcemia. Journal of Infectious Diseases 1974; 129: 538-544.

29. European Centre for Disease Prevention and Control. Diagnostic capacity for emerging and re-emerging viral diseases: Tender specifications 2008 (http://ecdc.europa. eu/Competitions/2007_019_PROC/CT_Diagnostic\% 20capacity\%20for\%20viral_final.pdf). Accessed 8 April 2008.

30. European Centre for Disease Prevention and Control. Risk assessment guidelines for infectious diseases transmitted on aircrafts: Tender specifications 2008 (http://ecdc.europa.eu/Competitions/2007_009_PROC/ TS_aircraft_final.pdf). Accessed 8 April 2008 . 